\title{
TRANSPOSIÇÃo DE PLÂNTULAS DE Alchornea castaneifolia (Willd.) A. Juss. DA REGENERAÇÃO NATURAL COMO ESTRATÉGIA DE PRODUÇÃO DE MUDAS EM VIVEIRO
}

\author{
Sheilly Raquelly Prado de Paula ${ }^{1}$, Ary Vieira de Paiva ${ }^{2}$, Álisson Sobrinho Maranho ${ }^{3}$
}

(recebido: 16 de outubro de 2010; aceito: 25 de janeiro de 2013)

RESUMO: Alchornea castaneifolia (Willd.) A. Juss. (Urana) é uma espécie nativa com potencial para recuperação de mata ciliar e para arborização urbana. Face à dificuldade de propagação dessa espécie e da carência de conhecimento sobre o seu comportamento em viveiro, neste estudo, objetivou-se avaliar a transposição de plântulas de Alchornea castaneifolia da regeneração natural como estratégia de produção de mudas em viveiro. A coleta ocorreu no município de Porto Acre - AC, e selecionadas 120 plântulas que foram divididas em três classes de altura $(<10 \mathrm{~cm}, 10-15 \mathrm{~cm},>15 \mathrm{~cm})$ e cultivadas em quatro substratos (terra, areia, resíduo de açaí+terra, Plantmax), em delineamento inteiramente casualizado, no esquema fatorial $3 \times 4$. Foi verificada a sobrevivência das plântulas e para o substrato areia o crescimento em altura $(\mathrm{H})$ e diâmetro do colo (DC) das mudas, a relação H/DC, a massa seca total, da parte aérea e das raízes entre as três classes de altura. A maior porcentagem de sobrevivência das plântulas de Alchornea castaneifolia foi observada no substrato areia (67\%), seguido do substrato resíduo de açaítterra (43\%). As plântulas que apresentaram maior crescimento em altura, diâmetro do colo, e produção de massa seca estavam contidas na classe acima de $15 \mathrm{~cm}$ de altura em substrato areia. Entretanto, a classe de $10-15 \mathrm{~cm}$ de altura apresentou $100 \%$ de sobrevivência das plântulas em substrato areia, e proporcionou também elevado crescimento. Recomenda-se, então, a transposição de plântulas na classe de 10-15 cm de altura, utilizando substrato areia para a propagação de Alchornea castaneifolia em viveiro.

Palavras-chave: Espécie florestal nativa, propagação, mata ciliar, silvicultura.

\section{TRANSPOSITION OF Alchornea castaneifolia (Willd.) A. Juss. SEEDLINGS FROM NATURAL REGENERATION AS A STRATEGY FOR SAPLINGS PRODUCTION IN NURSERY}

\begin{abstract}
Alchornea castaneifolia (Willd.) A. Juss. (Urana) is a native species with potential for restoration of riparian vegetation and urban forestry. Given the difficulty of its propagation and the lack of knowledge about their behavior in nursery, this study aimed to evaluate the transposition of Alchornea castaneifolia from natural regeneration as a strategy for saplings production in nursery. The collecting took place in Porto Acre - AC, and selected 120 seedlings, which were divided into three height classes $(<10 \mathrm{~cm}, 10$ $15 \mathrm{~cm},>15 \mathrm{~cm}$ ) and cultivated in four substrates (soil, sand, wasting açai + soil, Plantmax) in a completely randomized design in a $3 \times 4$ factorial design. We investigated the survival of seedlings and the growth in sand substrate to the characteristics height (H) and collar diameter (DC), the relationship H/DC, dry mass of shoots, roots and total between the three height classes of the seedlings. The highest percentage of Alchornea castaneifolia seedlings survival was observed in the sand substrate (67\%), followed by the wasting açai + soil substrate (43\%). Seedlings that showed greater growth in height, collar diameter and dry mass production were contained in the class above $15 \mathrm{~cm}$ in sand substrate. However, the 10-15 cm class of height presented $100 \%$ survival of seedlings in sand substrate and also provided high growth. It is therefore recommended the transposition of seedling in the 10-15 cm class using sand substrate for the propagation of Alchornea castaneifolia in nursery.
\end{abstract}

Key words: Native forest species, propagation, riparian vegetation, silviculture.

\section{INTRODUÇÃO}

A obtenção de mudas de variadas espécies nativas e em quantidades suficientes representa uma das principais restrições à implantação de plantios de elevada diversidade. Por isso, formas alternativas de produção de mudas são importantes no sentido de melhorar a qualidade dos plantios futuros (VIDAL, 2008).
A transposição de plântulas da regeneração natural se apresenta como uma técnica que pode ser usada de forma complementar à propagação de mudas em viveiros florestais. Segundo Nave (2005), no caso de viveiros comerciais, a fonte para o resgate de plântulas ou indivíduos jovens de espécies arbustivo-arbóreas podem ser locais não protegidos pela legislação onde elas germinem naturalmente, como no interior de florestas

${ }^{1}$ Engenheira Florestal - Universidade Federal do Acre/UFAC - BR 364, km 4, Distrito Industrial - 69.915-900 - Rio Branco, AC, Brasil sheilly_prado@hotmail.com

${ }^{2}$ Engenheiro Agrônomo, Professor DSc. em Recursos Florestais - Universidade Federal do Acre/UFAC - Centro de Ciências Biológicas e da Natureza BR 364, km 4, Distrito Industrial - 69.915-900 - Rio Branco, AC, Brasil - arypaiva1@yahoo.com.br

${ }^{3}$ Engenheiro Florestal, Mestrando em Ecologia e Manejo de Recursos Naturais - Universidade Federal do Acre/UFAC - BR 364, km 4, Distrito Industrial - 69.915-900 - Rio Branco, AC, Brasil - alissonsobrinho@hotmail.com

Cerne, Lavras, v. 19, n. 2, p. 323-330, abr./jun. 2013 
exóticas, nos aceiros em bordas de fragmentos, sob linhas de transmissão de energia elétrica que são situações periodicamente sujeitas à eliminação de indivíduos jovens de espécies nativas, por determinação legal ou de proteção. Até mesmo remanescentes de florestas nativas poderiam ser alvo desse resgate, desde que seja desenvolvida metodologia consistente, resgatando plântulas dentro de critérios técnicos devidamente desenvolvidos em trabalhos científicos.

Entre os principais benefícios associados à técnica de transplante de plântulas da regeneração natural visando à produção de mudas para os mais variados fins, estão: produção de mudas de espécies adaptadas, sob o ponto de vista ecológico, às suas regiões e não disponíveis em viveiros (espécies raras, ameaçadas de extinção, endêmicas, de diferentes formas de vida, etc.) e eliminação de etapas como beneficiamento, armazenamento e tratamentos pré-germinativos, que podem ser dispendiosas ou, muitas vezes, desconhecidas (VIDAL, 2008).

O êxito dos projetos de reflorestamentos comerciais ou com fins conservacionistas depende, entre outros fatores, da correta escolha das espécies. Em razão das múltiplas e complexas interações com o meio, a escolha das espécies será tanto mais correta quanto maior for o conhecimento que se tenha delas, principalmente no que se refere à ecologia e ao seu comportamento silvicultural (CUNHA et al., 2005). Apesar da importância das espécies nativas, poucos são os resultados de pesquisa sobre os seus aspectos silviculturais e autoecológicos que demonstrem seu potencial em programas de reflorestamento ou de recuperação de áreas degradadas (RÊGO; POSSAMAI, 2004), bem como para fins ornamentais, necessitando de pesquisas, principalmente quanto às suas exigências ao tipo de substrato (ARRIGONI-BLANK et al., 2003), luminosidade (PIEREZAN et al., 2012), temperatura (GUEDES; ALVES, 2011), dimensões de recipiente (VIANA et al., 2008), e exigências nutricionais (SORREANO et al., 2011).

Alchornea castaneifolia (Willd.) A. Juss. (Euphorbiaceae), conhecida popularmente como urana, possui hábito arbustivo ou arbóreo com 1,5-6,0 m de altura. As plantas são dioicas, ocasionalmente monoicas. Fruto obovado ou obovado-obcordado, pubescentes a glabros, com 2-3 sementes, elíptico-ovais, levemente muricadas (SECCO; GIULIETTI, 2004). A espécie é comumente encontrada em solos arenosos e associada a bancos de areia (SÁTIRO; ROQUE, 2007). É uma espécie típica de áreas inundáveis como margens de rios, restingas, matas de galeria, e matas de várzeas, estando periodicamente submersas pela enchente dos rios. No Brasil, há registros nos estados do Acre, Amazonas, Bahia, Pará, Maranhão e Mato Grosso. Na Bahia, foi coletada em bancos de areia, em Corumbá (MT) em solo seco, e no Maranhão em cerrado inundado. É uma espécie com potencial medicinal (SECCO; GIULIETTI, 2004), para arborização urbana e por se tratar de uma planta que fica meses submersa pela enchente dos rios, após desenvolvimento metodológico e científico, esta poderá ser incluída em projetos de recuperação de matas ciliares.

Diversas foram as tentativas com insucesso de propagação de Alchornea castaneifolia (Willd.) A. Juss. em viveiro, realizadas por estudos pelos autores desse trabalho, tanto via sexuada quanto assexuada, por estaquia com enraizamento induzido com fitohormônios (dados não publicados). Como a espécie fica submersa, em razão da enchente dos rios, foi observado em campo, que as plântulas coletadas provavelmente seriam das sementes dispersadas no ciclo anterior de frutificação e que, após a diminuição do nível da água, estas germinaram e formaram um grande banco de plântulas sob as matrizes.

Face à dificuldade de propagação dessa espécie e da importância dos estudos sobre o comportamento das espécies nativas com potencial para arborização urbana e recuperação de áreas degradadas, neste estudo, objetivouse avaliar a transposição de plântulas de Alchornea castaneifolia da regeneração natural como estratégia de produção de mudas em viveiro em diferentes classes de altura e substratos.

\section{MATERIAL E MÉTODOS}

O trabalho foi realizado no Viveiro de Produção de Mudas, no Parque Zoobotânico da Universidade Federal do Acre, cidade de Rio Branco, Estado do Acre, em casa de vegetação $(15 \times 7 \mathrm{~m})$ telada lateralmente e com cobertura de telha de amianto.

\subsection{Local de coleta das plântulas}

As plântulas foram coletadas às margens do rio Acre, no município de Porto Acre, Estado do Acre, localização 9³4'54"S e 67³1'45.24' O, sob uma população de árvores matrizes (Figura 1). Para a identificação correta da espécie, foram feitas exsicatas e enviadas para o herbário do Jardim Botânico do Rio de Janeiro. 


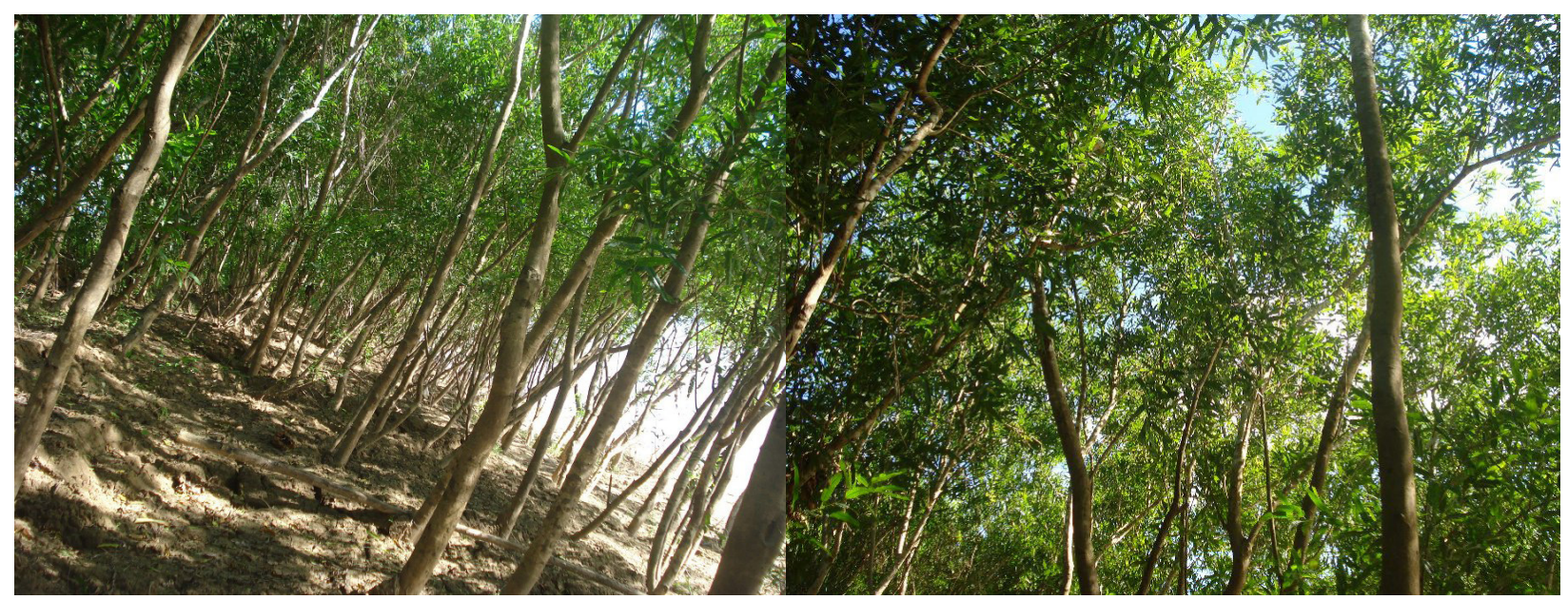

Figura 1 - População de Alchornea castaneifolia no local de coleta das plântulas, Porto Acre, AC, 2010.

Figure 1 - Population of Alchornea castaneifolia at the place of collecting seedlings, Porto Acre, Acre, 2010.

\subsection{Procedimentos}

Foram coletadas cerca de 200 plântulas manualmente, com auxílio de um facão, mas somente 120 apresentavam bom estado para o experimento, as quais foram divididas em três classes de altura (40 plântulas/ classe), Classe I: $<10 \mathrm{~cm}$; Classe II: $10-15 \mathrm{~cm}$; e Classe III: $>15 \mathrm{~cm}$, que foram levadas rapidamente ao viveiro da UFAC, sendo, então, lavadas e selecionadas as que se apresentavam normais, com todas as estruturas vitais intactas.

Após a seleção, as mudas foram conduzidas à casa de vegetação e, então, transplantadas em sacos plásticos de polietileno preto, tamanho $17 \times 25 \mathrm{~cm}$, com uma muda por recipiente e, logo após, irrigadas manualmente. Durante as primeiras semanas, a irrigação acontecia duas vezes ao dia e, posteriormente, uma vez ao dia, considerando a capacidade máxima que o substrato podia reter.

Os substratos utilizados foram terra de mata, areia, resíduo de açaí peneirado (oriundo do beneficiamento do fruto)+terra de mata $(1: 1 \mathrm{v} / \mathrm{v})$ e o comercial Plantmax.

$\mathrm{O}$ delineamento utilizado foi o inteiramente casualizado, no esquema fatorial $3 \times 4$ (três classes de altura e quatro substratos), totalizando 12 tratamentos, com 10 repetições de uma plântula, totalizando 120 mudas no experimento. Foram calculados os percentuais de sobrevivência para cada substrato, e mortalidade a cada trinta dias.

Em razão da alta mortalidade das plântulas em determinadas classes e substratos, foi feito o desmembramento dos dados e analisado estatisticamente o crescimento das plântulas cultivadas no substrato areia, em forma de delineamento inteiramente casualizado simples, comparando-se as classes de altura. Os dados obtidos foram submetidos à análise de normalidade, homogeneidade e variância, e as médias comparadas pelo teste de Tukey ao nível de $5 \%$ de probabilidade.

Para todas as análises utilizou-se os programas estatísticos Assistat 7.5 (ASSIS, 2008), e Bioestat 5.0 (AYRES et al., 2007).

As características utilizadas para avaliação das plântulas no substrato areia, nas três classes de altura, foram a altura da parte aérea $(\mathrm{H}-\mathrm{cm})$, diâmetro do colo (DC - mm), e, aos 90 dias da transposição, foi realizada a coleta do material, sendo determinados o peso de massa seca total (PMST - g muda $^{-1}$ ), peso de massa seca da parte aérea (PMSPA - $\mathrm{g} \mathrm{muda}^{-1}$ ), peso de massa seca das raízes $\left(\right.$ PMSR $\left.-\mathrm{g} \mathrm{muda}^{-1}\right)$, e a relação entre altura da parte aérea e o diâmetro do colo (H/DC).

A H e o DC foram medidos aos 30, 60 e 90 dias da instalação do experimento com um escalímetro/trena, a partir do nível do substrato até a gema apical e por um paquímetro de precisão de $0,01 \mathrm{~mm}$, respectivamente. As determinações do PMSPA e do PMSR foram efetuadas a partir do material seco em estufa de ventilação forçada a $80^{\circ} \mathrm{C}$, por aproximadamente 24 horas. O PMST foi obtido a partir da soma das duas partes. A relação H/DC foi determinada pela razão dos valores das duas características para cada muda e depois obtida a média de todos eles para a comparação entre os tratamentos.

Cerne, Lavras, v. 19, n. 2, p. 323-330, abr./jun. 2013 


\section{RESULTADOS E DISCUSSÃO}

De modo geral, a sobrevivência das 120 mudas coletadas da regeneração natural aos 90 dias foi de $33,33 \%$, e para cada substrato e classe demonstrada na Figura 2.

A sobrevivência das mudas variou mais entre os substratos do que entre as classes de altura. A maior porcentagem de sobrevivência foi observada no substrato areia, com média das classes de $67 \%$, seguido do substrato resíduo de açaí+terra com média de $43 \%$. A classe de altura com maior sobrevivência foi a II, no substrato areia, com $100 \%$ de sobrevivência.

A maior sobrevivência observada no substrato areia, provavelmente está relacionada com o fato de essa espécie possuir registro em áreas arenosas e mesmo em bancos de areia (SÁTIRO; ROQUE, 2007), como foi verificado na área de ocorrência dos indivíduos coletados, no qual as matrizes estão presentes na beira do rio, colonizando uma grande área. Diante disso, o substrato areia propiciou a condição mais aproximada dessas plântulas que já estavam adaptadas em campo.

Nave (2005) obteve $44,1 \%$ de sobrevivência de 590 indivíduos resgatados, de diversas espécies arbustivo-arbóreas no inverno e 70,9\% de 506 indivíduos resgatados no verão, para classe entre $4-20 \mathrm{~cm}$ de altura, e percebeu ainda que com o aumento da classe de altura aumentou também a mortalidade, o que possivelmente está relacionado com o maior dano radicular causado aos indivíduos de maior porte no momento do resgate.

A sobrevivência e a capacidade das plântulas de se adaptarem às variações do ambiente, em condições naturais, estão relacionadas com os seus atributos morfológicos e fisiológicos (FENNER, 1987). Esses atributos incluem especialmente área foliar, biomassa, disposição das folhas e ramos, taxa fotossintética e respiratória, e eficiência no uso da água (GARWOOD, 1996). Quando indivíduos são transplantados para viveiro de produção de mudas, estes também seriam afetados pelos mesmos aspectos, incluindo ainda os tratos culturais e o substrato utilizado.

A transposição de plântulas dificilmente é realizada, e pode ocorrer em casos onde a espécie apresenta muita dificuldade de propagação, como a Alchornea castaneifolia, porém trabalhos vêm mostrando essa possibilidade atualmente. Viani e Rodrigues (2007) estudaram a sobrevivência em viveiro de 110 espécies nativas retiradas de um remanescente florestal, e concluíram que a técnica complementar é viável, principalmente pela dificuldade de obtenção de propágulos das espécies nativas. Verificaram ainda maior taxa de sobrevivência entre as espécies pioneiras e variação para as classes de altura entre as espécies.

Na Figura 3, estão os percentuais de mortalidade acumulada por substrato e por classe de altura, ao longo dos 90 dias de avaliação.

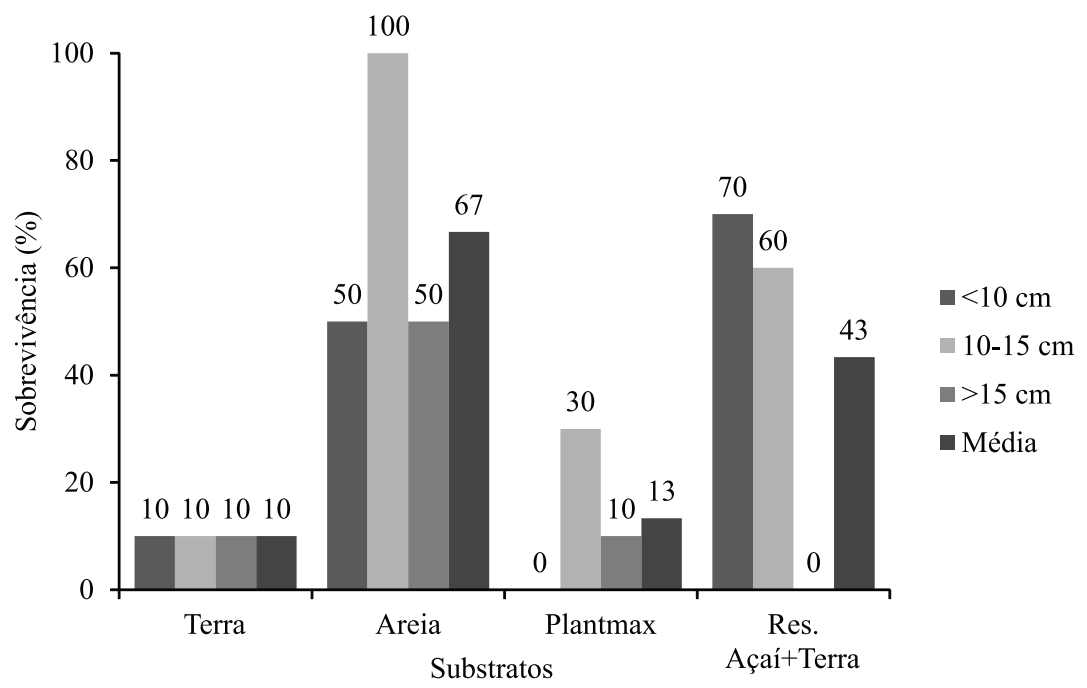

Figura 2 - Sobrevivência de mudas de $A$. castaneifolia, aos 90 dias, em diferentes substratos e classes de alturas, transplantadas da regeneração natural para o viveiro.

Figure 2 - Saplings survival of A. castaneifolia, at 90 days, in different substrates and classes of height, transplanted from natural regeneration to the nursery.

Cerne, Lavras, v. 19, n. 2, p. 323-330, abr./jun. 2013 

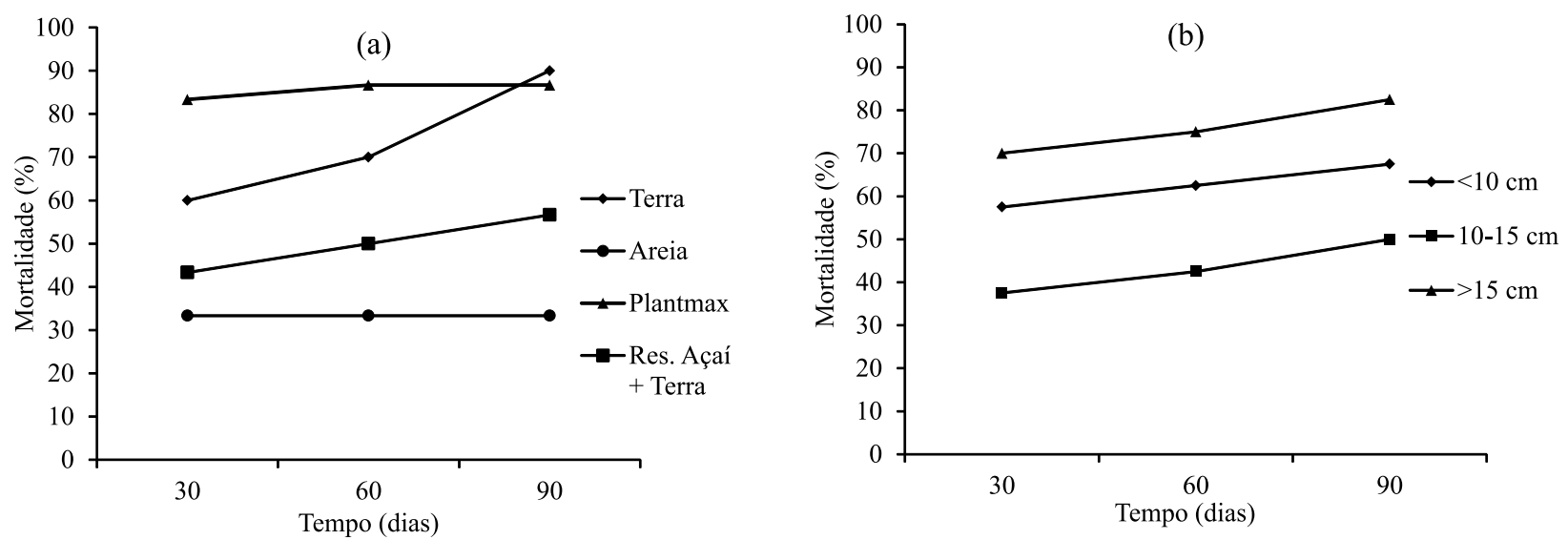

Figura 3 - Mortalidade acumulada de mudas de A. castaneifolia por substrato (a) e por classe de altura (b), transplantadas da regeneração natural para o viveiro.

Figure 3 - Cumulative mortality of saplings of A. castaneifolia by substrate (a) and class of height (b), transplanted from natural regeneration to the nursery.

A maior porcentagem de mortalidade para todos os substratos foi verificada logo nos primeiros trinta dias após a transposição das mudas para o viveiro, o que se deve, provavelmente, à aclimatação das plântulas ao ambiente e ao novo substrato. Aos trinta dias, o substrato comercial Plantmax apresentou a maior mortalidade de mudas, seguido do substrato terra, e a menor foi para a areia que se manteve constante até os noventa dias do ensaio, acima de $30 \%$.

Entre as classes de altura, a maior mortalidade ocorreu na classe acima de $15 \mathrm{~cm}$ a partir dos trinta dias, e a menor mortalidade na classe intermediária, entre $10-15 \mathrm{~cm}$.

Diante disso, as mudas entre $10-15 \mathrm{~cm}$ de altura cultivadas no substrato areia, se adaptaram melhor às condições do viveiro de produção de mudas, quando comparada com as outras classes e substratos, apesar de a areia não ser boa fonte de nutrientes, mas é a condição que mais se aproxima do ambiente onde foram resgatadas as plântulas de Alchornea castaneifolia.

A análise de variância do substrato areia, nas três classes de altura, para o crescimento em altura e diâmetro do colo e a relação altura/diâmetro do colo aos 90 dias pode ser observada na Tabela 1 .

O maior crescimento médio em altura das plântulas foi observado na classe de altura acima de $15 \mathrm{~cm}$ de altura, o que foi influenciado pelo tamanho das plântulas no momento do transplante, já que pertenciam a de maior classe.
Tabela 1 - Crescimento médio em altura $(\mathrm{H})$, diâmetro do colo (DC) e relação altura/diâmetro do colo $(\mathrm{H} / \mathrm{DC})$ de mudas de Alchornea castaneifolia no substrato areia em três classes de altura, aos 90 dias.

Table 1 - Mean growth in height $(H)$, collar diameter (DC) and relation of height/collar diameter $(H / D)$ of saplings of Alchornea castaneifolia in sand substrate in three classes of height, at 90 days.

\begin{tabular}{lccc}
\hline $\begin{array}{c}\text { Classes } \\
\text { de altura }\end{array}$ & $\begin{array}{c}\mathrm{H} \\
\left(\mathrm{cm} \mathrm{plântula}^{-1}\right)\end{array}$ & $\begin{array}{c}\mathrm{DC} \\
\left(\mathrm{mm}_{\text {plântula }}{ }^{-1}\right)\end{array}$ & $\mathrm{H} / \mathrm{DC}$ \\
\hline$<10 \mathrm{~cm}$ & $35,70 \mathrm{~b}$ & $3,36 \mathrm{a}$ & $10,68 \mathrm{~b}$ \\
$10-15 \mathrm{~cm}$ & $36,44 \mathrm{~b}$ & $3,16 \mathrm{a}$ & $11,41 \mathrm{~b}$ \\
$>15 \mathrm{~cm}$ & $48,88 \mathrm{a}$ & $3,60 \mathrm{a}$ & $13,70 \mathrm{a}$ \\
\hline $\mathrm{F}$ & $5,14^{*}$ & $1,31^{\mathrm{ns}}$ & $7,67^{* *}$ \\
$\mathrm{CV} \%$ & 19,5 & 14,9 & 11,0 \\
\hline
\end{tabular}

* significativo a $5 \%$, e **a $1 \%$ de probabilidade e ${ }^{\text {ns }}$ não significativo pelo Teste F de Snedecor; as médias seguidas pelas mesmas letras não diferem entre si significativamente, pelo teste de Tukey, ao nível de 5\% de probabilidade; CV\%: Coeficiente de Variação.

Quanto ao crescimento em diâmetro do colo, não houve diferença estatística entre as classes de altura das plântulas, mas a maior média foi obtida na classe acima de $15 \mathrm{~cm}$ de altura.

Na classe III $(>15 \mathrm{~cm})$, obteve-se a maior relação H/DC, de 13,70, diferenciando-se estatisticamente das demais, indicando menor proporção entre o crescimento

Cerne, Lavras, v. 19, n. 2, p. 323-330, abr./jun. 2013 
entre as duas partes e qualidade inferior às mudas das classes I e II que apresentaram relação H/DC mais equilibradas, indicando serem mudas mais aptas para ir ao campo.

Cada espécie tem sua própria faixa de oscilação para relação H/DC. Carneiro (1995) recomenda que esses valores devem situar-se entre 5,4 e 8,1 para a espécie Pinus taeda, sendo, assim, mudas com desenvolvimento mais equilibrado entre as duas partes e com maior qualidade $\mathrm{e}$ capacidade de sobrevivência em campo. $\mathrm{O}$ autor comenta ainda que as mudas devem apresentar um diâmetro mínimo em relação à altura da parte aérea, e quanto menor for essa relação (neste caso, mais próximo de 5,4 ) melhor será a qualidade das mudas.

O crescimento em altura da parte aérea aos 30,60 e 90 dias após a transposição das plântulas, está exposto na Figura 4.

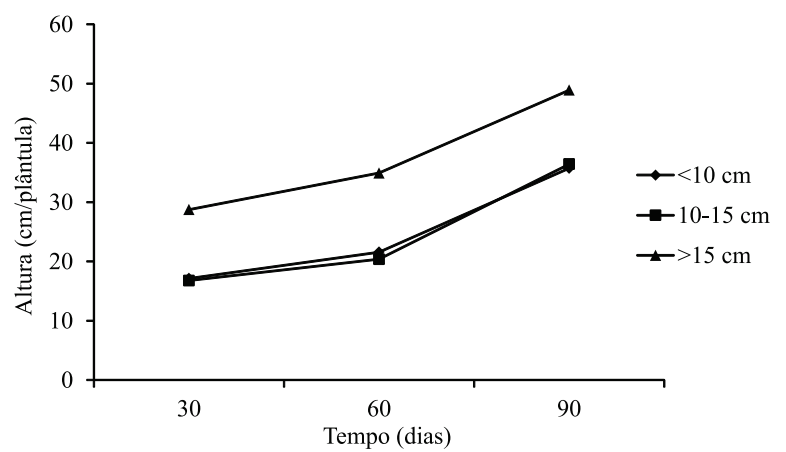

Figura 4 - Crescimento médio em altura de Alchornea castaneifolia aos 30, 60 e 90 dias após a transposição para o substrato areia, em três classes de altura.

Figure 4-Mean growth in height of Alchornea castaneifolia at 30, 60 and 90 days after the transposition to sand substrate, in three classes of height.

A espécie apresentou tendência de crescimento em altura semelhante nas três classes, apesar de a classe III $(>15 \mathrm{~cm})$ ter se destacado entre as demais durante todo o período de observação das plântulas no viveiro. Vidal (2008) observou maior crescimento de plântulas transplantadas em classes menores de até $20 \mathrm{~cm}$, abrangendo as classes deste trabalho.

O crescimento diamétrico avaliado aos 30,60 e 90 dias pode ser observado na Figura 5.

O crescimento diamétrico foi maior para as plântulas na classe de altura acima de $15 \mathrm{~cm}$, sendo mais

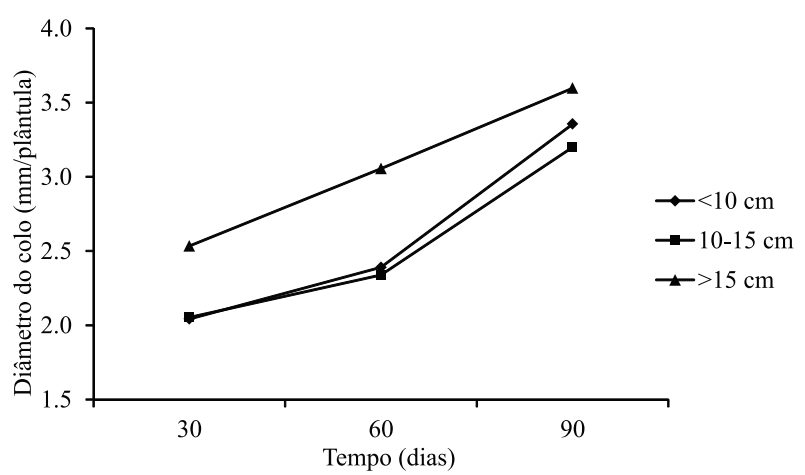

Figura 5 - Incremento diamétrico de Alchornea castaneifolia aos 30, 60 e 90 dias após a transposição para o substrato areia, em três classes de altura.

Figure 5-Diameter increase of Alchornea castaneifolia at 30, 60 and 90 days after the transposition to sand substrate, in three classes of height.

expressivo no intervalo entre os 30 e 90 dias de observação. As plântulas nas outras duas classes apresentaram crescimento diamétrico semelhante.

A produção de massa seca é um parâmetro bastante consistente e utilizado na avaliação das espécies quanto às variações dos fatores externos. Na Tabela 2, é apresentada a produção total de massa das mudas cultivadas no substrato areia, aos 90 dias.

Tabela 2 - Produção média de massa seca $\left(\mathrm{g}\right.$ plântula $\left.{ }^{-1}\right)$ da parte aérea (PMSPA), da raiz (PMSR) e total (PMST) de Alchornea castaneifolia, aos 90 dias.

Table 2 - Mean dry weights ( $g$ seedling ${ }^{-1}$ ) of shoot (PMSPA), roots (PMSR) and total (PMST) of Alchornea castaneifolia, at 90 days.

\begin{tabular}{lccc}
\hline $\begin{array}{c}\text { Classes } \\
\text { de altura }\end{array}$ & PMSPA & PMSR & PMST \\
\hline$<10 \mathrm{~cm}$ & $0,923 \mathrm{a}$ & $0,602 \mathrm{a}$ & $1,526 \mathrm{a}$ \\
$10-15 \mathrm{~cm}$ & $0,930 \mathrm{a}$ & $0,569 \mathrm{a}$ & $1,499 \mathrm{a}$ \\
$>15 \mathrm{~cm}$ & $1,285 \mathrm{a}$ & $0,735 \mathrm{a}$ & $2,020 \mathrm{a}$ \\
\hline $\mathrm{F}$ & $1,672^{\text {ns }}$ & $0,702^{\text {ns }}$ & $1,391^{\text {ns }}$ \\
$\mathrm{CV} \%$ & 37,1 & 41,8 & 36,4 \\
\hline
\end{tabular}

ns: não significativo pelo Teste $\mathrm{F}$, a $5 \%$ de probabilidade; as médias seguidas pelas mesmas letras não diferem entre si significativamente, pelo teste de Tukey, ao nível de 5\% de probabilidade; CV\%: Coeficiente de Variação. 
A produção média de massa seca total das plântulas no substrato areia não se diferenciou entre as classes de altura, bem como de cada uma de suas partes, apesar de a maior biomassa ter sido obtida na classe de maior altura.

Os resultados deste trabalho apontam para a realização de mais estudos sobre os mecanismos de propagação de Alchornea castaneifolia, bem como do seu comportamento em viveiro, para gerar protocolos de propagação por outros métodos, e da definição sobre o melhor período e coleta de plântulas em campo, já que são poucos os estudos sobre transposição de plântulas no Brasil. Possivelmente, com avanços metodológicos nos estudos de transposição, as taxas de mortalidade poderão diminuir, facilitando, assim, a utilização desta e outras espécies de interesse no meio urbano e para a recuperação de matas ciliares.

\section{CONCLUSÕES}

A maior porcentagem de sobrevivência das plântulas de Alchornea castaneifolia por transposição da regeneração natural para o viveiro foi observada no substrato areia.

As plântulas que apresentaram maior crescimento estavam contidas na classe acima de $15 \mathrm{~cm}$ de altura em substrato areia. Entretanto, a classe de $10-15 \mathrm{~cm}$ de altura apresentou $100 \%$ de sobrevivência das plântulas e proporcionou, também, elevado crescimento.

Recomenda-se, então, a transposição de plântulas na classe de 10-15 cm de altura em substrato areia, para a propagação dessa espécie em viveiro.

\section{REFERÊNCIAS}

ARRIGONI-BLANK, M. de F.; CARVALHO FILHO, J. L. S. de; BLANK, A. F.; SANTOS NETO, A. L. dos. Efeitos do substrato e luminosidade na emergência e desenvolvimento de mudas de jasmim-laranja (Murraya exotica). Revista Ciência Agronômica, Fortaleza, v. 34, n. 1, p. 5-12, 2003.

ASSIS, F. de. Assistat 7.5. Campina Grande: UFCG, 2008. Disponível em: $<$ http://www.assistat.com>. Acesso em: 15 jun. 2009.

AYRES, M.; AYRES JUNIOR, M.; AYRES, D. L.; SANTOS, A. A. S. Bioestat 5.0: aplicações estatísticas nas áreas de ciências biológicas e médicas. Belém: Sociedade Civil Mamirauá, 2007.

CARneIRO, J. G. de A. Produção e controle de mudas florestais. Curitiba: UFPR/FUPEF, 1995. 451 p.
CUNHA, A. O.; ANDRADE, L. A. de; BRUNO, R. de L. A.; SILVA, J. A. L. da; SOUZA, V. C. de. Efeitos de substratos e das dimensões dos recipientes na qualidade das mudas de tabebuia impetiginosa (mart. Ex d.c.) Standl. Revista Árvore, Viçosa, v. 29, n. 4, p. 507-516, jul./ago. 2005.

FENNER, M. Seedlings. The New Phytologist, Cambridge, v. 106, p. 35-47, 1987.

GARWOOD, N. C. Functional morphology of tropical tree seedlings. In: SWAINE, M. D. (Ed.). The ecology of tropical forest tree seedlings. Paris: UNESCO/Parthenon, 1996. p. 59-129.

GUEDES, R. S.; ALVES, E. U. Substratos e temperaturas para o teste de germinação de sementes de Chorisia glaziovii (O. Kuntze). Cerne, Lavras, v. 17, n. 4, p. 525-531, 2011.

NAVE, A. G. Banco de sementes autóctone, resgate de plantas e plantio de vegetação nativa na fazenda Intermontes, Município de Ribeirão Grande, SP. 2005. 218 p. Tese (Doutorado em Recursos Florestais) - Escola Superior de Agricultura "Luiz Queiroz", Piracicaba, 2005.

PIEREZAN, L.; SCALON, S. P. Q.; PEREIRA, Z. V. Emergência de plântulas e crescimento de mudas de jatobá com uso de bioestimulante e sombreamento. Cerne, Lavras, v. 18, n. 1, p. 127-133, 2012.

RÊGO, G. M.; POSSAMAI, E. Efeito do substrato e da temperatura sobre a germinação e vigor de sementes do jequitibá-rosa (Cariniana legalis). Colombo: EMBRAPA, 2004. (Comunicado Técnico, 127).

SÁTIRO, L. N.; ROQUE, N. A família Euphorbiaceae nas caatingas arenosas do médio São Francisco, BA, Brasil. Acta Botanica Brasílica, Feira de Santana, v. 22, n. 1, p. 99-118, 2008.

SECCO, R. de S.; GiUlietti, A. M. Sinopse das espécies de Alchornea (Euphorbiaceae, Acalyphoideae) na Argentina. Darwiniana, Buenos Aires, v. 43, n. 1/4, p. 315-331, 2004.

SORREANO, M. C. M.; MALAVOLTA, E.; SILVA, D. H.; CABRAL, C. P.; RODRIGUES, R. R. Deficiência de macronutrientes em mudas de sangra d'água (Croton urucurana, Baill.). Cerne, Lavras, v. 17, n. 3, p. 347-352, 2011.

Cerne, Lavras, v. 19, n. 2, p. 323-330, abr./jun. 2013 
VIANA, J. S.; GONÇALVES, E. P.; ANDRADE, L. A.; OLIVEIRA, L. S. B.; SILVA, E. O. Crescimento de mudas de Bauhinia forficata Link. em diferentes tamanhos de recipientes. Floresta, Curitiba, v. 38, n. 4, p. 663-671, 2008.

VIANI, R. A. G.; RODRIGUES, R. R. Sobrevivência em viveiro de mudas de espécies nativas retiradas da regeneração natural de remanescente florestal. Pesquisa Agropecuária Brasileira, Brasília, v. 42, n. 8, p. 1067-1075, ago. 2007.

VIDAL, C. Y. Transplante de plântulas jovens como estratégia de produção de mudas para a restauração de áreas degradadas. 2008. 171 p. Dissertação (Mestrado em Recursos Florestais) - Escola Superior de Agricultura "Luiz de Queiroz", Piracicaba, 2008.

Cerne, Lavras, v. 19, n. 2, p. 323-330, abr./jun. 2013 